Gestión y Estrategia

Gestão e Estratégia

Management and Strategy

\title{
TRASGRESIÓN DE DERECHOS HUMANOS A RAíz DEL TRÁFICO ILEGAL DE COLTÁN en el Departamento del Guainía ${ }^{1}$
}

TRANSGRESSÕES DOS DIREITOS HUMANOS COMO RESULTADO DO TRÁFICO ILEGAL DE COLTAN NO DEPARTAMENTO DE GUAINIA² Transgressions of Human Rights as a Result of the lllegal Traffic Coltan in the Department of Guainía ${ }^{3}$

Hermann David González Garzón ${ }^{4}$

Escuela Superior de Guerra

\section{CIENCIA Y PODER AÉREO}

ISSN 1909-7050 / E- ISSN 2389-2468 / Volumen 10 / Enero-Diciembre de 2015/ Colombia/ Pp. 1-260 Recibido: 22/07/2015

Aprobado evaluador interno: 09/10/201

Aprobado evaluador externo: 27/11/2015

Doi: http://dx.doi.org/10.18667/cienciaypoderaereo.492 
CIENCIA Y PODER AÉREO | Revista Científica de la Escuela de Postgrados de la Fuerza Aérea Colombiana | Vol. 10 | Enero - Diciembre de 2015

\section{Para citar este artículo:}

González, H. (2016). Trasgresión de derechos humanos a raíz del tráfico ilegal de coltán en el Departamento del Guainía. Ciencia y Poder Aéreo, 10 (1), 151-168. Doi: http:// dx.doi.org/10.18667/cienciaypoderaereo.492

\footnotetext{
'Artículo de reflexión derivado de la investigación presentada como trabajo de grado para optar al título de Magíster en Derechos Humanos y Derecho Internacional de los Conflictos Armados de la Escuela Superior de Guerra, siendo producto del proyecto de Investigación "Derecho Operacional como instrumento eficaz para la protección de la población civil y la seguridad jurídica institucional como individual en Colombia" vinculado al grupo de investigación "DDHH, DICA y Justicia"; inscrito en Colciencias, avalado por la Escuela Superior de Guerra. Bogotá, Colombia.
}

${ }^{2}$ Artigo de reflexão derivado da pesquisa apresentada como uma opção para obter o título de Mestre em Direitos Humanos e Direito Internacional na Escola Superior de Guerra, sendo o produto do projeto de pesquisa "Direito Operacional como um instrumento eficaz para a proteção da população civil e a segurança jurídica institucional como individual na Colômbia "ligado ao grupo de pesquisa" DH, DICA e Justiça "; registrado em Colciencias, aprovado pela Escola Superior de Guerra. Bogotá Colômbia.

${ }^{3}$ Reflection article derived from research presented as an option to obtain the title of Master of Human Rights and International Law of Armed Conflict at Colombian War College, being the product of the research project "Operational Law as an effective instrument for the protection of civilians and institutional legal security as an individual in Colombia "inked to the research group" Human Rights, DICA and Justice"; registered in Colciencias, endorsed by the Colombian War College. Bogotá, Colombia.

${ }^{4}$ Oficial en grado de Capitán de la Fuerza Aérea Colombiana. Magíster en Derechos Humanos y Derecho Internacional de los Conflictos Armados. Escuela Superior de Guerra. Correo electrónico: hergon77@ hotmail.com
Resumen: el centro de análisis del presente artículo, lo constituye explorar y ahondar en el impacto que sobre la población y el medio ambiente del departamento del Guainía tiene la explotación y el mercado ilegal del coltán, dada la posible violación a los derechos humanos y a la integridad de los habitantes por la presión de las redes criminales que allí operan en conexión con los tentáculos del tráfico internacional del mineral. El estado actual por la explotación del coltán deriva un examen del que se concluye que los derechos humanos de sus pobladores observan serias lesiones por el flujo migratorio que la ilegalidad desencadena y las condiciones forzosas de trabajo a las que se somete a estos grupos humanos. A través de tres secciones enmarcadas en un ejercicio descriptivo, analítico y evaluativo de esta realidad, se parte de ubicar al lector social y jurídicamente respecto a lo que esta parte del territorio nacional representa para las rutas ilícitas y cómo, la ausencia de un marco jurídico consistente que atenúe el flagrante fenómeno de desamparo de quienes caen presas del crimen organizado, agudiza aún más los efectos nocivos de la explotación ilegal en el período 2010-2012. Con un volumen de información muy puntual que amplía el espectro de análisis respecto a lo que la explotación del coltán colombiano está representando en el mercado negro global, se estudia la planeación de componentes, derroteros y correctivos que a futuro, puedan cobrar importancia estratégica en la inserción de una política pública que reduzca la amenaza a la vida de los pobladores de la zona y vele por la dignificación de los trabajadores del sector minero y su calidad de vida.

Palabras clave: cachiveras; coltán; lesiones sistémicas; mercados de violencia.

Resumo: o foco de análise deste artigo, é explorar e aprofundar o impacto na população e no ambiente que tem a exploração ilegal e o mercado de coltan no departamento de Guainía, tendo em conta a possível violação dos direitos humanos e da integridade dos habitantes sob a pressão de redes criminosas que operam em conexão com os tentáculos do tráfego internacional do mineral. Do estado atual na exploração de coltan deriva um exame que concluiu que os direitos humanos da sua população observam lesões graves do fluxo de imigração que desencadeia a ilegalidade e as condições de trabalho forçado a que estão sujeitos estes. Através de três seções enquadradas num exercício descritivo, analítico e avaliativo dessa realidade, presume-se localizar o leitor social e legalmente sobre o que representa esta parte do país para as vias ilícitas e como a ausência de um quadro jurídico consistente para atenuar o fenómeno da negligência flagrante daqueles que são vítimas de crime organizado, agrava ainda mais os efeitos nocivos da extração ilegal no período de 2010-2012. Com um volume de informações muito específicas que ampliam o espectro de análise sobre o que a exploração de coltan está representando no mercado negro global, se estuda o planejamento de componentes, caminhos e correções que a future possam cobrar importância estratégica na inserção de uma política pública para reduzir a ameaça para a vida dos moradores da área e garantir a dignidade dos trabalhadores no setor de mineração e sua qualidade de vida.

Palavras-chave: cachiveras; coltan; lesões sistêmicas; mercados violência.

Abstract: This article explores and delves into the impact on the population of the department of Guainía is exploitation and illegal Coltán market given the possible violation of human rights and the integrity of the people by the pressure of criminal networks operating there in connection with the tentacles of international mineral traffic. The Coltán exploitation testifies that the human rights of its people experience severe injuries migratory flow illegality forced triggers and working conditions to those subjected to these groups. Through three sections structured in a descriptive, analytical and evaluative exercise of this reality, it is assumed the reader locate socially and legally about what this part of the country accounting for illicit routes and how the absence of consistent legal framework that mitigates the blatant neglect phenomenon of those who fall prey to organized crime, further exacerbates the harmful effects of illegal logging, in the period 20102012. With considerable information that broadens the scope of analysis about what Colombian Coltán exploitation is representing global illegal market, we study the planning component, and corrective paths to the future, to collect strategic importance in the insertion of a public policy to reduce the threat to the lives of the residents of the area and ensure the dignity of workers in the mining sector and their quality of life.

Key Words: Cachiveras; Coltan; Systemic Injury; Violence Markets. 


\section{Introducción}

Tres aristas -descripción, análisis y evaluación-, signan el desglose de este examen para nutrir futuros estudios que contrarresten y prevengan mayores lesiones a los derechos humanos de la población en referencia en esta vasta ubicación del territorio nacional. A partir de los propósitos derivados del objeto central de este análisis como son indagar por las conductas violatorias en el ámbito social, económico y cultural generadas por la explotación ilegal de este mineral en estas comunidades más determinar el grado de afectación en sus pobladores y explorar el impacto del mercado ilegal en la cotidianidad de los nativos de este territorio, se emprende el análisis de la realidad de los derechos humanos en esta zona del país.

Es así como se advierte que la extracción de materia prima lleva consigo problemas no únicamente ambientales sino de impacto social que por ende y alrededor de su comercialización, muchas veces encierran un mercado de muerte dadas las redes que en un país como Colombia, atravesado por un conflicto interno, crean un círculo de violencia. En el país, es tradicional la problemática de la explotación minera del oro y las esmeraldas pero menos conocida la del coltán, cuya naturaleza en sí misma no es un mineral sino un nombre acuñado que fusiona una serie de minerales, explicación que en detalle se desarrolla más adelante. Así, dadas las afectaciones dispares sobre las poblaciones locales por la explotación de este recurso que se ha elevado popularmente a la categoría de mineral, el departamento de Guainía presenta un grado de vulnerabilidad que compromete seriamente los derechos humanos; ante tal gravedad, hasta hace poco las autoridades locales y nacionales están tomando conciencia de las implicaciones que para la vida de sus pobladores tiene la falta de un código de conducta respecto a esta actividad en aras de la puesta en marcha de los mecanismos suficientes para que este mercado en verdad derive beneficio a quienes deben llegar los réditos de este producido y se traduzca en crecimiento para la región.

En virtud de lo anterior, este artículo como se enunció inicialmente, cifra su eje de estudio en indagar por el contexto que enmarca esta problemática así como el impacto que sobre la vida de pobladores y personas allegadas por la cadena humana de la explotación y el mercado del mineral, se registra.

Problema de investigación: ¿cuáles son las consecuencias a nivel de afectación a los DDHH de los pobladores de las regiones vinculadas con la explotación del mineral de coltán en el Departamento del Guaina en el período 2010 a 2012?
Este interrogante se justifica, en la medida en que la reducida información disponible sobre impactos sanitarios y ambientales asociados en la explotación minera de coltán, y sobre consecuencias sobre los recursos naturales hace necesario su examinación e investigación científica. Particularmente para el caso de la Orinoquia se habla del crecimiento de la minería aurífera en la región de la Orinoquía colombiana. Ya para el caso de estudio en los últimos 15 años, según diagnóstico de algunas publicaciones de prensa empezó la llamada "fiebre por el oro azul o las tierras raras" (Revista Semana, 2013), el coltán, que se trata de la combinación de minerales valiosos, "la columbita y tantalita, de donde salen el tantalio y el niobio, minerales preciados en la fabricación de celulares y otros aparatos electrónicos" (Revista Semana, 2013).

Tipo de investigación: el presente informe obedece a un estudio cualitativo e interdisciplinario e involucra la descripción de la problemática del coltán, el análisis de su tratamiento jurídico en el contexto de los DDHH y sus impactos socios económicos y ambientales en el Departamento de Guainía en el período de estudio 2010-2012.

Métodos de recolección de información: para el desarrollo de esta pregunta científica, se hace necesario acudir a la revisión documental de informes oficiales de control policivo así como del amaláis de informes de medios de prensa sobre la materia.

A partir de dichos informes disponibles se da cuenta como las autoridades locales aseguran que "el frente 16 FARC regula la explotación de una mina de coltán, cerca del parque nacional Puinawai, próxima al resguardo Semán" (Revista Semana, 2013). El acceso a dicha zona es muy difícil porque no hay vías, "el río tiene tramos que no son navegables y por aire las guerrillas bajan a todo el que no tenga su autorización. Ni siquiera pudieron volver los funcionarios de Parques Nacionales". (Revista Semana, 2013).

Así, lo que se revela inicialmente de dichas aproximaciones e informe son una serie afectaciones a DDHH a la salud y al medio ambiente de poblaciones humanas y recursos naturales, no dimensionada ni evaluada a la fecha, toda vez que tan solo se cuentan con informes de prensa sobre la materia, y la ausencia de regulación consolidada sobre el mineral del coltán en Colombia, hace necesario un abordaje investigativo que permita determinar y evaluar la medidas de intervención estatal sobre minería ilegal presente, así como el alcance e implementación de políticas públicas relacionadas.

Concepto de violación de DDHH: para estos efectos es importante primeramente partir de un concepto de 
CIENCIA Y PODER AÉREO | Revista Científica de la Escuela de Postgrados de la Fuerza Aérea Colombiana | Vol. 10 | Enero - Diciembre de 2015

cómo se entiende aquí el concepto de violación de derechos humanos, para lo cual y en relación al objeto de estudio, se acude a la definición prevista por la Corte Interamericana de Derechos Humanos CIDH, cuando considera que en casos que involucran al medio ambiente y la salud pública, "un hecho ilícito violatorio de los derechos humanos que inicialmente no resulte imputable directamente a un Estado, sino obra de un particular, que puede acarrear la responsabilidad internacional del Estado, no por ese hecho en sí mismo, sino por falta de la debida diligencia para prevenir la violación o para tratarla" (CIDH, 2001, p. 172).

Es importante advertir que como se trata de un escenario de estudio que involucran presencia de actores armados insurgentes se sigue aquí el criterio dado por la Cruz Roja Internacional que defiende el reconocimiento de tres deficiencias en lo relacionado con la protección del medio ambiente durante los conflictos armados. Primero, la definición de daño ambiental inadmisible es demasiado restrictiva y poco clara; segundo, la existencia de incertidumbres jurídicas en lo relacionado con la protección de elementos del medio ambiente como bienes de carácter civil; y tercero, la aplicación del principio de proporcionalidad, según el cual el daño al medio ambiente constituye "daño colateral", también es problemático.

La Cruz Roja Internacional considera entonces que una forma de abordar algunas de las inadecuaciones del DIH podría ser la aplicación del derecho internacional del medio ambiente durante los conflictos armados. (Bothe, Bruch, Diamond y Jensen, 2010). Para este propósito, se aborda en tres secciones del informe la descripción, el análisis y la evaluación del fenómeno en el departamento del Guainía desde la ubicación geográfica, el sondeo de las rutas del tráfico, el marco jurídico y el radio de compromiso de los derechos humanos mediante la documentación fidedigna, la consulta de fuentes confiables y la exploración de datos de contraste y referenciación válida. Todo esto, para concluir finalmente, en unos hallazgos de aporte en la comprensión integral sobre la problemática descrita y la planeación de componentes, derroteros y correctivos que cobren importancia estratégica en la inserción de una política pública.

\section{Tráfico ilegal del Coltán en el departamento del Guainía}

\section{Naturaleza del Coltán}

No es un mineral sino un término o abreviatura comercial para nombrar una serie de minerales que, en alta concentración, tienen los elementos tantalio (Ta) y niobio (Nb). En la actualidad, han sido identificadas más de
70 mineralizaciones que contienen estos elementos con composiciones químicas y estructuras cristalinas diferentes. Las mineralizaciones del Ta y Nb, económicamente más valiosas e importantes son la Tantalita y la Columbita. El niobio, tiene otra mineralización importante conocida como el piro cloró. Resumiendo, columbita y tantalita, junto a otros minerales, se les conoce informalmente por la abreviatura. Tanto el tantalio como el niobio; presentan un color gris brillante que tiende a tornarse azul cuando están en contacto con el aire; pertenecen al grupo de los metales de transición, con alta densidad y peso, buena ductilidad, resistentes a la corrosión y, magníficos conductores térmicos y de electricidad. Son empleados actualmente para la fabricación de componentes de alta tecnología y en aleaciones metalúrgicas súper resistentes (Marín, 2013). Estos minerales en el medio ambiente se consiguen a poca profundidad, donde son recogidos, triturados y luego extraídos (El Tiempo, 2009).

Teniendo en cuenta que, el denominado coltán en realidad no es un solo mineral como se ha dicho, sino un término usado originalmente en África para nombrar una serie de minerales, el profesor Thomas Cramer de la Universidad Nacional explica que, menas ${ }^{1}$ con contenidos de Tantalio ( $\mathrm{Ta}$ ) y Niobio (Nb) podrían esperarse en todo el Oriente colombiano ya que la formación geológica de la zona corresponde a una de las más antiguas de la Tierra, como parte del denominado Escudo de Guayana que se extiende por Venezuela, Brasil y la parte oriental de Colombia. Este Escudo limita con el río Orinoco al Norte y al Oriente y con la Selva Amazónica al Sur. Tiene más de 1.000 millones de años y fue formado por rocas cristalinas que sufrieron procesos de orogénesis, es decir, de formación de montes -de los que ya no queda nada- que a su vez movilizaron magmas, hoy concentrados en regiones como la Amazonía, Vichada y Guainía. Venezuela, Colombia y Brasil tienen una geología similar, por eso es probable que compartan las mencionadas mineralizaciones, solo que no se conocen, pues poco, muy poco, se han estudiado. (Marín, 2013).

\footnotetext{
${ }^{1}$ Mineral de base del que es posible extraer otro mineral de mayor pureza e importancia económica. La molibdenita (sulfuro de molibdeno), por ejemplo, es la principal mena del molibdeno. ${ }_{2}$. Minerales que presentan interés económico en un yacimiento. Este concepto se opone al de ganga. En general, es un término que se refiere a minerales metálicos y que designa al mineral del que se extrae el elemento de interés. Para poder aprovechar mejor la mena, suele ser necesario su tratamiento, que en general comprende dos etapas: el tratamiento en el sitio de mina para aumentar la concentración del mineral en cuestión (procesos hidrometalúrgicos, flotación, entre otros), y el tratamiento metalúrgico final, que permita extraer el elemento químico en cuestión (tostación, electrolisis, entre otros).
} 
Zona Chocó y zona oriente

Área inicial: 22,3 millones $\mathrm{Ha}$

Área final: 17,6 millones $\mathrm{Ha}$

(202 bloques - 15,4\% del territorio nacional)

Potencial minero

Mineral de Uranio
Mineral de Coltan
Mineral de oro
Mineral de hierro
Mineral de platino

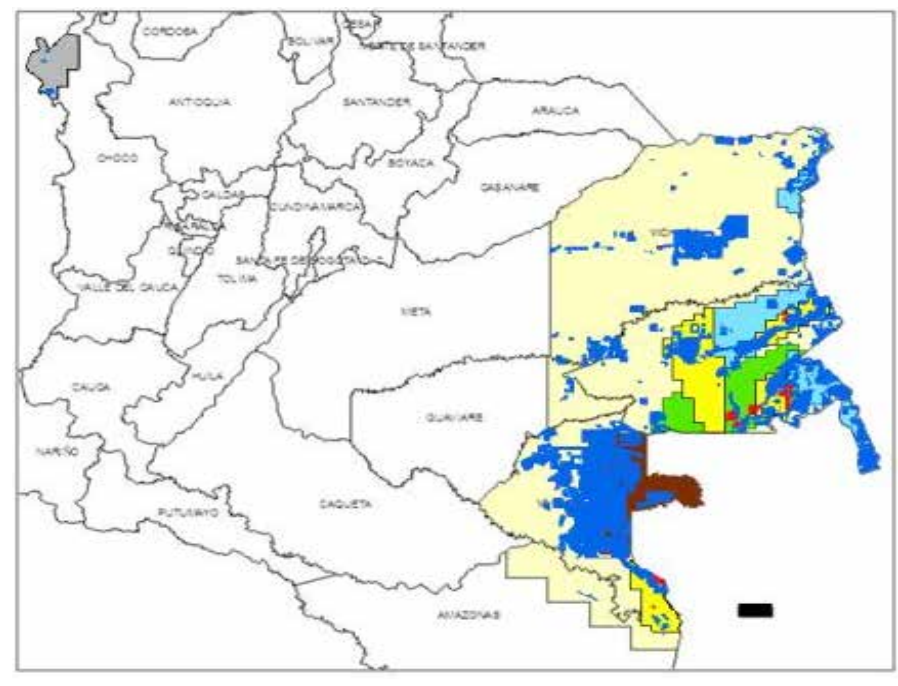

Actividad minera

- Solicitudes vigentes: 961 (4,7 millones de $\mathrm{Ha}$ )

Títulos mineros: 48 (81 mil Ha)

Figura 1. Áreas estratégicas mineras.

Fuente: Agencia Nacional de Minería (citado por Orduz, 2012).

Así, con lo anteriormente mencionado, la Figura 1 muestra el potencial minero en el departamento y en especial, el mineral con abreviatura comercial conocido como coltán motivo del presente estudio.

Este compuesto de minerales es conocido en el mundo como el 'oro azul', el petróleo del barro o el nuevo maná. Los últimos informes científicos registran que en solo nueve países se habían encontrado importantes yacimientos de coltán: Congo, Australia, Tailandia, Brasil, Canadá, Egipto, Sudáfrica, Nigeria y Malasia. Pero, recientemente, se conoció que existía este mineral en Colombia y en la República Bolivariana de Venezuela. Así mismo, se habla de importantes hallazgos del mineral en el altiplano boliviano. De acuerdo con los analistas internacionales, el $80 \%$ de las reservas mundiales de coltán se encuentran en la República Democrática de Congo, mientras que Australia sólo posee un 10\% y Tailandia, Brasil, Venezuela y Colombia, un 5\%, pero hasta el momento no hay una información oficial. No hay estudios científicos que corroboren esas reservas y solo se conoce por información de indígenas, campesinos y colonos que existen yacimientos de coltán en los departamentos del Vaupés, Guaviare, Guainía y Vichada. También se cree en otras regiones del país existen yacimientos del mineral (El Nuevo Siglo, 2012). Por otro lado, el Instituto Colombiano de Geología y Minería no tiene estudios confiables ni suficientes que determinen las zonas productoras, el alcance básico de las reservas y la forma como se debería llevar a cabo su extracción y el pago de regalías e impuestos.

Dadas estas características, está considerado como un recurso no renovable altamente estratégico, que al igual que los hidrocarburos, no abundan en toda la corteza terrestre. El coltán es extraído a través de procesos primitivos similares a los del oro en minas artesanales. En los yacimientos trabajan hombres, mujeres y niños excavando grandes agujeros en hileras para sacar el mineral del subsuelo y luego lavan el lodo (Revista Semana. 2009).

Para el caso colombiano, hasta hoy la explotación del coltán se ha realizado a cielo abierto y de manera artesanal, sin la debida vigilancia y control Estatal, lo que ha permitido que "grupos alzados en armas y terceros ajenos a nuestro país se beneficien y enriquezcan a raíz de la denominada vacuna que se le cobran a los mineros artesanales por la explotación y comercialización de estos recursos, dinero que partiendo de la legalización de esta actividad en Colombia entraría a través de impuestos al patrimonio Estatal". (Galeano, 2011)

\section{Usos dados al mineral coltán}

El tantalio en combinación con óxido de tantalio, posee una excelente propiedad de almacenar carga eléctrica temporal y liberarla cuando se necesita, permite diseños muy delgados y pequeños; se emplea para fabricar la gran mayoría de componentes electrónicos consiguiendo una mayor eficiencia y miniaturización. El Ferro-Tantalio importante en la metalurgia, pues mejorar propiedades anticorrosivas y, a su vez, mantienen la ductilidad. El niobio tiene menos aplicaciones electrónicas su mayor uso es en forma de Ferro - Niobio como aleación para aceros, y como carburo de niobio en aceros para herramientas de mecanizado de alta velocidad su alta demanda es para aleaciones de acero de alta resistencia mecánica, aceros de baja aleación y aceros inoxidables en los que el $\mathrm{Nb}$ es utilizado para el 
CIENCIA Y PODER AÉREO | Revista Científica de la Escuela de Postgrados de la Fuerza Aérea Colombiana | Vol. 10 | Enero - Diciembre de 2015

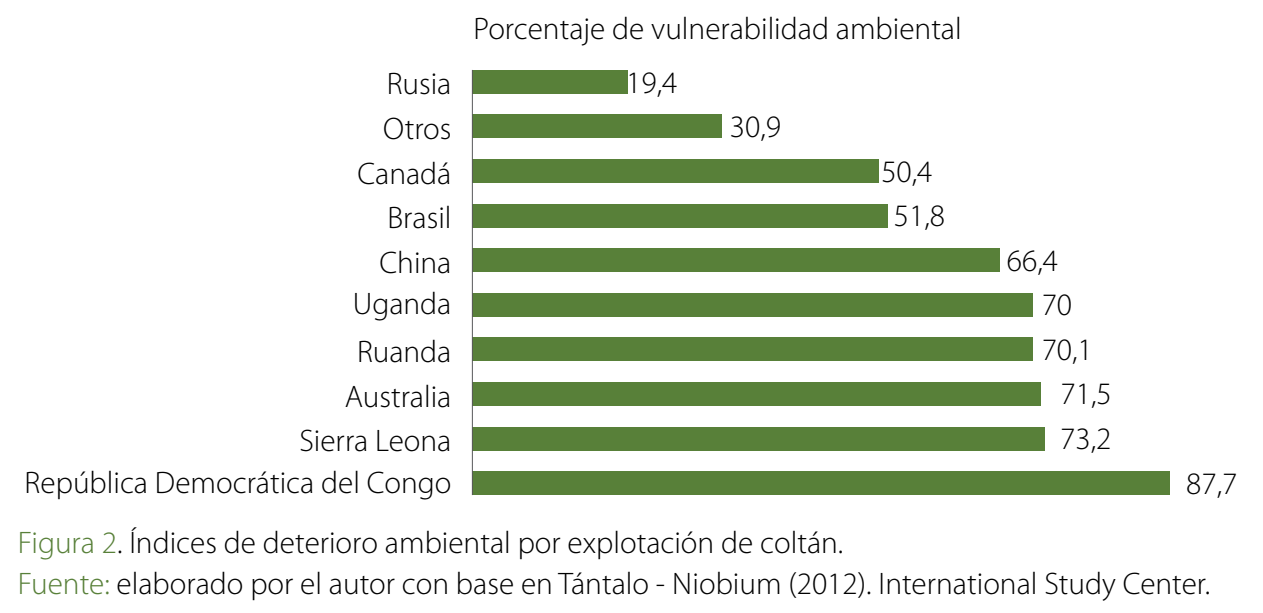

control del tamaño del grano, ya que mejora las propiedades mecánicas y la relación resistencia-peso del acero. Estos aceros son utilizados para aumentar la durabilidad de puentes, torres, columnas, estructuras elevadas y tuberías de hidrocarburos (Marín, 2013).

En la práctica, el tantalio es usado para fabricar todo tipo de aparatos electrónicos, como condensadores y chips indispensables para computadores e iPods, es imprescindible, para formar aleación con el acero en la construcción de los oleoductos. Se aplica en la construcción de baterías cada vez más pequeñas, permitiendo que su carga dure mucho más tiempo (El Tiempo, 2009). Este elemento también está presente en los televisores de plasma, en los mp3, al igual que en los GPS. Igualmente, en los satélites, en armas teledirigidas, en centrales atómicas, en aleaciones para turbinas de aeronaves y en partes de trenes de alta velocidad. (Marín, 2013).

Como se observa, es un material idóneo para uso extraterrestre en la Estación Espacial Internacional y en futuras plataformas y bases espaciales, indispensables para los teléfonos celulares, juegos de consolas, esto es realizado por seis plantas procesadoras que hay en el mundo ubicadas en Alemania, China, Japón, Tailandia, Kazajstán, y en los Estados Unidos. Se ha utilizado también en marcapasos, es mucho mejor conductor que el cobre; ultra refractario, capaz de soportar temperaturas muy elevadas, unos 3.000 grados centígrados. Además es muy maleable, dúctil y de gran dureza. Esto hace que este mineral sea tan apetecido y ante un mundo de permanentes cambios y desarrollos electrónicos su utilización se hace cada vez más indispensable. (Marín, 2013).

\section{Colombia con relación a la problemática internacional del coltán}

La problemática descrita lleva a que la comunidad internacional exprese su preocupación específicamente en lo que compete a la violación a los Derechos Humanos por cuanto esta explotación ilegal propicia un daño sistémico a la población local donde tiene lugar esta actividad minera.

Los índices de afectación medioambiental se reflejan en la Figura 2 que describen márgenes inaceptables de degradación.

El último informe del Centro de Estudio Internacional del Tantalio-Niobio en Bélgica², país que está asumiendo una actitud rectificadora dado que alrededor del mineral ha mantenido con el Congo una relación de ilegalidad comercial lo que ha obligado a las autoridades a observar vigilancia, advierte que en alguna regiones de países latinoamericanos como Colombia y Venezuela donde también se está dando mayor muestra de territorios ricos en coltán, los cinturones criminales que emplean a mujeres embarazadas a ejercer como puentes humanos en las rutas que más adelante se describen, ha prendido las alarmas de la Inteligencia mundial (Diaz-Struck y Poliszuk, 2012).

Por esta razón, en un esfuerzo del Gobierno belga por contrarrestar los efectos de los compradores internacionales sobre los derechos de quienes habitan las zonas que son el blanco de los grupos criminales que en torno a la explotación minera proliferan, se han emitido permanentes comunicados alertando sobre el enorme daño que los compradores ocasionan a estas poblaciones al comprar el mineral fuera del escenario permitido.

Se quiere evitar que en regiones como aquellas donde ya existen conflictos, se sume uno más por las reservas de

\footnotetext{
${ }^{2}$ Este país europeo observa fuerte vínculos con la problemática del coltán debido a que la Compañía belga Cogecom sprl ha monopolizado el mercado dejándole millonarios réditos lo que hace que Bélgica sea el pretexto de la firma Somigl y Cogear para centrar sus negocios ficticios.
} 


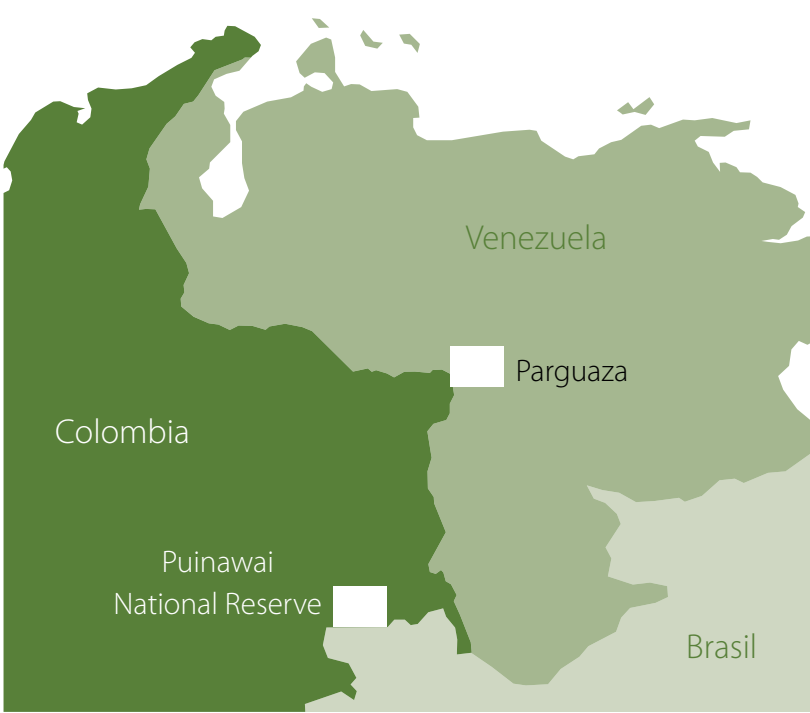

Figura 3. Puntos estratégicos del coltán.

Fuente: The International Consortium of Investigative Journalists (2012).

coltán tal como ha sucedido en los países centroafricanos y en la República Democrática del Congo y Ruanda donde sus vecinos solían ser la fuente de tonelajes significativos. Pero la guerra civil, saqueando los parques nacionales y exportando los minerales, diamantes y otros recursos naturales para financiar las milicias ha obligado al Centro de Estudio Internacional del Tantalio-Niobio a hacer una llamada a sus miembros para que tengan cuidado de obtener las materias primas de fuentes legales. De manera que si el narcotráfico y los grupos ilegales armados que operan en la ruta entre Brasil, Colombia y Venezuela ponen a la población civil en el centro de este mercado perverso, pueden suscitarse violaciones sistemáticas a la integridad de sus pobladores para quienes la muerte reta diariamente (Diaz-Struck y Poliszuk, 2012).

Alrededor de este mercado, la población nativa e indígena más los niños, las mujeres y los labriegos están siendo sometidos a condiciones de explotación laboral donde el contrabando, el tráfico de drogas y las bandas dedicadas a sostener el mercado negro del mineral, no se sujetan a ley alguna (Gómez, 2012).

\section{Rutas del tráfico ilegal del mineral}

Colombia no está siendo ajena a la fiebre mundial por la explotación, aprovechamiento y usufructo del coltán. A pesar de ser un mineral desconocido e inexplorado en el territorio, se convierte en una rica fuente de ingresos para los países que lo poseen.

La búsqueda del mineral trasnocha a rastreadores de todo el mundo, ya que mueve mucho dinero. En el depar- tamento del Guainía ha generado una ola de comerciantes, especuladores y grupos armados alrededor de este negocio. Pero por otro lado, representa una nueva oportunidad de negocios en Latinoamérica, donde se podrían exportar "con un proceso de legalización y tecnificación unas 300 toneladas mensuales", dice Vladimir Villegas, uno de los fundadores de Coltán Sas, la única empresa legal creada en Colombia para comercializar este mineral. Esa sociedad le está pidiendo al Gobierno que reglamente lo necesario para explotar y exportar el coltán, un negocio que hoy está al garete pero puede valer muchos miles de millones de dólares. (Revista Semana, 2009). Al igual en Vichada sí hay una licencia vigente de explotación. Le fue otorgada, en 1995, a Rafael Alberto Rodríguez, quien obtuvo el título para explotar en el sitio conocido como El Caney de los Cristales, cerca del río Guaviare. Hoy, su licencia se denomina de 'arenas negras', lo que le permite exportar la piedra (Quintero, 2012).

La primera vez que se habló del coltán en el departamento fue en el 2009, cuando la entonces alcaldesa, Martha Zulia Parra, tuvo un grave problema con las comunidades indígenas, que se le rebelaron porque ella se oponía a que sacaran el mineral, por el que intermediarios de multinacionales pagaban en la selva hasta 20 millones de pesos por tonelada. Un año después, cuando fueron decomisadas las primeras 17 toneladas de coltán en Puerto Inírida, llegó a ese municipio la multinacional Disercom: "Resultó que el segundo de esa empresa era uno de los hermanos Cifuentes Villa, asociado al cartel de Sinaloa, de México", aseveró el Comandante de Inteligencia de la Policía en Puerto Inírida, el capitán Rafael Fernández (Quintero, 2012).

En 2011, el General Óscar Naranjo, entonces director de la Policía Nacional, prendió las alarmas al revelar que el cartel de Sinaloa y las FARC estaban apareciendo "como dos aliados para la explotación del coltán, según lo evidencian los correos hallados en distintos dispositivos electrónicos de las FARC. Ese marcado interés puesto de manifiesto por Naranjo se ve ahora cristalizado en la mega mina a cielo abierto en que se ha convertido Cerro Tigre. Unos 100 metros cuadrados de montaña han sido desbastados, según lo confirman fotos aéreas tomadas por la Policía. Para el año 2012 el Gobernador del departamento, Óscar Rodríguez sostiene: "lo que está ocurriendo es que el Estado se ha dormido en asumirlo y a las autoridades militares locales se lo están camuflando como tungsteno, un mineral que sí tiene una licencia de explotación y que es mucho más barato", agrega. Luis Bernal, ingeniero de la Agencia Nacional de Minería, dice que también influye la falta de conocimiento sobre el coltán en el país. "Eso hace que a muchas autoridades que no tienen equipos de medición les metan gato por liebre; exportan tungsteno cuando 
CIENCIA Y PODER AÉREO | Revista Científica de la Escuela de Postgrados de la Fuerza Aérea Colombiana | Vol. 10 | Enero - Diciembre de 2015

realmente es coltán, que cuesta ocho veces más" (Quintero, 2012, párr.16). Se puede evidenciar entonces que las variables del problema son muchas, no se cuenta con los conocimientos sobre el mineral, adicional no hay equipos que ayuden a la detección del mineral y se encuentran muchos intereses detrás del mismo.

De acuerdo con el Instituto Colombiano de Geología y Minería, el cálculo que se tenía para el año 2009 es que Colombia sería el poseedor del 5 por ciento de las reservas del mundo. Por eso, y para la época el Gobierno decidió congelar la aprobación de al menos 300 solicitudes que existían para explotarlo ante el Instituto (Londoño, 2009).

De otro lado, mientras que en el país, ya se habían detectado algunas explotaciones ilegales de este producto, cuyo valor en el mercado internacional dependía de su nivel de pureza. Sin embargo, esta entidad se limitó, únicamente a congelar cualquier intento por explotarlo, tal vez por la posibilidad de que su control se convierta en una nueva causa de violencia y contrabando, por su ubicación en una zona donde históricamente han hecho presencia grupos armados ilegales, pero no se preocupó por realizar los diferentes estudios para determinar las verdaderas existencias del mineral en la zona (El Tiempo, 2009).

Se dice que para solo el año 2009 pudo haber movido más de 40 millones de dólares, de manera ilegal. Lo cierto es que desde el año 2005 este mineral está siendo extraído en varias regiones del oriente de Colombia para exportarlo a comercializadores internacionales. Una vez extraído el mineral sale de contrabando, especialmente a Estados Unidos, Alemania, Holanda, Bélgica y Kazajistán. Por otra parte, China buscó en esta época por medio de sus empresas, apoderarse de la producción de las minas de coltán mediante la compra de los títulos de las minas. (Revista Semana, 2009).

De acuerdo a lo que enuncia en su artículo la Revista Semana (2009), sostiene que se colocaron esos intereses en probables yacimientos en el Vichada, especialmente en la producción de resguardos indígenas de la Orinoquía. Así mismo, en el año 2006 comerciantes llegaron hasta zonas de Vichada y Guainía para promover la explotación de coltán en regiones cercanas al Orinoco o sus afluentes, como la minería de este material no estaba reglamentada en el país, los comerciantes se ampararon en registros falsos y en que parte de los yacimientos están en resguardos indígenas para comprar y vender el producto. Así, mediante el barequeo ${ }^{3}$ en ríos y laderas debían el mineral, que después

${ }^{3}$ Actividad que se contrae al lavado de arenas por medios manuales sin ninguna ayuda de maquinaria o medios mecánicos y con era sacado a Bogotá, donde una tonelada pudo costar en este año entre 40.000 y 60.000 dólares. Estos comerciantes tenían que pagar un impuesto de 2.000 a 2.500 dólares por tonelada a las autodefensas y la guerrilla que está en algunas de esas zonas, mensualmente se podría estar exportando entre 10 y 25 toneladas de coltán.

En una investigación realizada por El Espectador (2011), para el año 2010 los frentes primero, séptimo, 16 y 39 de las FARC, el Ejército Revolucionario Popular Anticomunista de Colombia (ERPAC, del capo Cuchillo), 'Los Paisas,' 'Los Rastrojos'y otros criminales en Urabá se encontraban metiéndole la mano a este negocio. Comerciantes denunciaban que debían pagarles un impuesto de US\$2.000 a US\$2.500 por tonelada a los grupos ilegales que custodian el coltán. Por otro lado, son los brasileños quienes ilegalmente se adentran en territorio colombiano para comercializar el mineral, dice el informe de Inteligencia, que además indica que Puerto Carreño es un punto de tránsito para el mineral que ingresa desde Venezuela con destino hacia Bogotá o el Pacífico, donde es exportado. Así mismo, en Guainía hay reportes de que las primeras autoridades departamentales y locales de Puerto Inírida serían dueños y socios de dragas para explotación minera, "quienes para no verse involucrados en actividades ilícitas habrían solicitado licencias para la explotación aurífera a nombre de los capitanes indígenas de las comunidades de Danta, Zamuro, Venado", entre otros (El Espectador, 2010, párr.7). De acuerdo con este informe se puede apreciar claramente que detrás del negocio se encuentran las guerrillas, bandas criminales y las mismas autoridades departamentales, en razón a lo lucrativo del negocio.

En el año 2012 en un reportaje realizado por el diario El Tiempo se encontró que "La guerrilla le paga a los indígenas para que extraigan los minerales. Con tanto desempleo, mucha gente accede a explotar ilegalmente en las minas", palabras del señor comandante de la Armada Nacional, almirante Roberto García Márquez. Al igual que las FARC también aprovechan la frontera con Venezuela para sacar los minerales ilegalmente. Esta extracción ilegal de minerales ha sido usada por la guerrilla para su financiamiento y su fortalecimiento (Sarralde, 2012).

El Ministro de Minas y Energía Cárdenas, dice: lo que puede existir es explotación ilícita de minerales. Este problema está creciendo en Colombia, como crece en Perú, Ecuador y Bolivia. Hoy, incautamos la maquinaria, pero a los dos o tres días, por trámites y mecanismos de protec-

el objeto de separar y recoger metales preciosos contenidos en dichas arenas. Igualmente es permitida la recolección de piedras preciosas y semipreciosas por medios similares. 
ción judicial que tiene nuestro sistema legal, esa maquinaria queda habilitada de nuevo. La extracción ilícita de minerales son dos cosas: una minería informal, que es la tradicional, de mineros artesanales, buscando esencialmente carbón y oro. Así, esos mineros lo que necesitan es una legalización, un proceso de formalización en el que pueden trabajar bajo el amparo de un título minero a cambio de que cumplan con estándares ambientales, paguen regalías y erradiquen prácticas de trabajo indebidas. La otra minería es la criminal, que es la patrocinada por los grupos al margen de la ley - BACRIM, paramilitares, guerrilla - como fuente de financiamiento. Una minería que casi siempre utiliza maquinaria sofisticada y costosa, que genera un gran daño ambiental. Como tiene tantas facetas similares al narcotráfico, el tratamiento que tenemos que darle es análogo (Nullvalue, 2012).

El frente 'Acacio Medina' de las FARC -una facción del frente 16-, que, según la Policía, cambió el polvo blanco de la coca por las arenas negras de donde se extrae la piedra azul grisáceo. Y donde las autoridades mineras dicen no haber encontrado depósitos importantes de estos minerales en el país, pero todo indica que las FARC explotan, desde el año 2009, una mina que hoy emplea a 600 personas (unos 500 indígenas y 100 colonos) y que produce cada mes un promedio de 60 toneladas, según cálculos de la policía local. (Quintero, 2012).

La mina está a unas cuatro horas por río del raudal donde está el Comandante'Julián', en una montaña conocida como Cerro Tigre, entre las comunidades indígenas de Zancudo y Guacamaya, en pleno corazón del Parque Nacional Puinawai, a un día y medio por río de la capital del Guainía. A esta explotación se le suma que los comerciantes del mineral deben pagarle el impuesto de salida a la guerrilla, que cobra 5.000 pesos por cada kilo. Además de este gasto, hay que pagar 1.000 pesos por kilo más para bajar la piedra de la mina hasta Puerto Cambalache, y otros 1.200 pesos por kilo para transportarla hasta Puerto Nariño, en Guainía, donde la mercancía es entregada a otro intermediario, que deberá llevarla, por tierra, hasta Villavicencio y luego a Bogotá. En la capital, el coltán nuevamente cambia de manos y es entregado a una red que lo saca hasta un puerto, que las autoridades no han determinado, para luego llegar a los mercados internacionales. Por estas consideraciones, el único obstáculo visible para traficar es un pequeño campamento de la Infantería de Marina que está cerca de Puerto Inírida y muy lejos de la mina, con unos diez soldados. Pero esta no es la única ruta. Hay otra que, en lugar de bajar por el río hasta Puerto Inírida, sube contra la corriente por comunidades indígenas, hasta llegar a San José del Guaviare. Y de allí, por tierra hasta Villavicencio (Quintero, 2012).
Las autoridades regionales y el Gobierno conocen lo que está pasando en Zancudo pero aún no han hecho nada. La razón principal es la dificultad de acceso. Llegar a Puinawai es muy difícil: sólo se puede por el río Guainía o por el río Inírida. Pero si se prefiere este último, hay que sobrepasar seis raudales que obligan a los lancheros a sacar la lancha del río y caminar 100 metros hasta llegar a un lugar donde se pueda volver a navegar. La única forma de llegar a Zancudo es por este camino (García, 2012).

Para sacar la arena negra de Puinawai, los compradores tienen que enfrentar una larga travesía por caños ocultos que conectan a Guainía con otros departamentos. Antes los compradores bajaban por el río Inírida hasta la capital de Guainía. Después de eso, a tan sólo unos kilómetros, conquistan el río Guaviare y llegan a Vichada. Ahí legalizan la mercancía con unos títulos mineros otorgados en el departamento. Pero la estrategia se les dañó hace unos dos años cuando las autoridades ambientales empezaron a controlar el río y a exigir licencias ambientales que respaldarán los títulos mineros. Fue en ese momento cuando el destino se volvió Villavicencio. (García, 2012).

No obstante, transitar la ruta del coltán tiene un precio fijado por varios frentes de las FARC. Cada tonelada que compran en Puinawai cuesta 9 millones de pesos, y para sacarla tienen que pagarle cinco millones de pesos al frente Acacio Medina de las FARC. Desde Zancudo los compradores remontan el río Inírida hasta llegar a dos caseríos del departamento del Guaviare: Puerto Flores o Charras. Ahí se encuentran con dos frentes de la guerrilla. El primero es el 44 de las FARC que cobra una vacuna de tres millones de pesos por cada tonelada y después el frente 16 de las FARC que cobra 2 millones. (García, 2012).

Ya en el Guaviare, los compradores utilizan trochas antiguas de la guerrilla que los llevan hasta San José del Guaviare. Ahí tienen que pagarle un millón de pesos al Frente Séptimo de las FARC, la última columna de este grupo armado que domina la ruta del coltán. En la capital del Guaviare, el control pasa a las manos de los paramilitares, que cobran un peaje de 200 mil pesos por cada tonelada transportada hasta Villavicencio por vía terrestre. Al conquistar la meta, los compradores ya han pagado por una tonelada de coltán más de 20 millones de pesos, sin contar lo que gastan en la logística para transportarlo. Aun así, el negocio sigue siendo jugoso: actualmente en el mercado oficial una tonelada de coltán puede costar más de 50 millones de pesos, una cifra que se eleva en el mercado negro. (García, 2012).

En la Figura 4 se ilustra la ubicación de la reserva del parque nacional natural Puinawai, sitio actual afectado por la explotación ilegal de mineral, y donde su geogra- 
CIENCIA Y PODER AÉREO | Revista Científica de la Escuela de Postgrados de la Fuerza Aérea Colombiana | Vol. 10 | Enero - Diciembre de 2015

fía dificulta a las autoridades del área, poder ejercer un control efectivo de la zona en los corredores que utilizan los compradores del mineral, debido a las difíciles condiciones del clima, la topografía y la vegetación de selva predominante en el sitio.

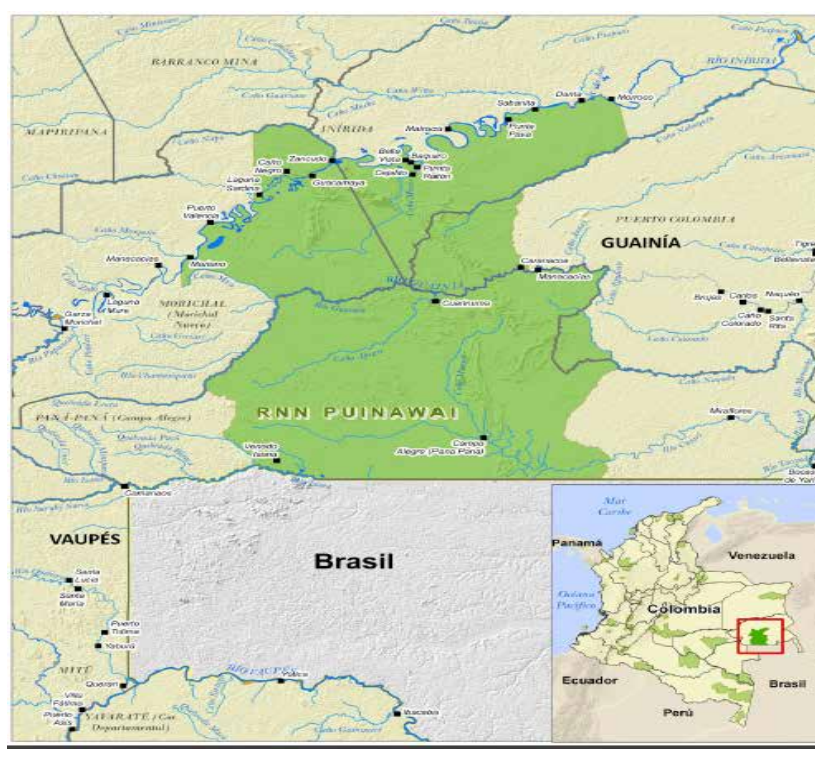

Figura 4. Ubicación geográfica de la Reserva Nacional Natural Puinawai.

Fuente: Parques Nacionales Naturales de Colombia. (2012).

El director de la Policía, general José Roberto León Riaño, explicó que "en el caso del coltán, reflejan los distintos correos hallados en diferentes dispositivos de las FARC que hay un interés marcado por esta explotación ilegal en zonas de reserva indígena". El consultor en seguridad y defensa y analista internacional, Coronel en retiro del Ejército, John Marulanda, urgió al Gobierno nacional, legislar y regular la explotación del coltán en Colombia, pues en estos momentos lo extraen los carteles del narcotráfico, las bandas emergentes al servicio del narcotráfico y las FARC, además de traficantes nacionales e internacionales: "el cartel de Sinaloa mexicano tiene muchos nexos con los carteles y redes del narcotráfico en Colombia y con las FARC y a través del coltán que sale ilegalmente del país, buscan legalizar sus dineros producto de las actividades de la venta de clorhidrato de cocaína y heroína, entre otras drogas" (El Nuevo Siglo, 2012, párr. 31).

\section{Incautaciones efectuadas del mineral coltán en el área}

Según datos de la Policía Nacional (ver Figura 5), se registraron operaciones que dan cuenta de minas intervenidas, capturas, kilogramos de coltán incautado en la zona, como se registra en la Figura 5. (Policía Nacional Dirección de Carabineros y Seguridad Rural, 2012).

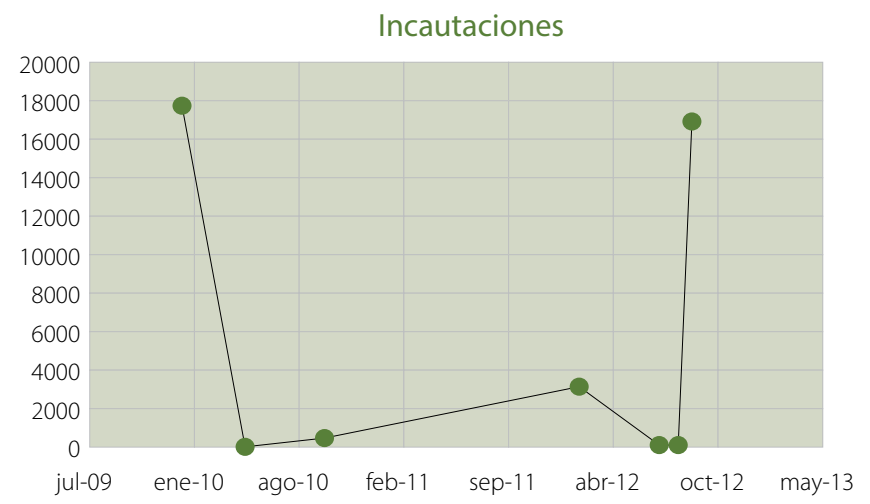

Figura 5. Incautaciones efectuadas.

Fuente: Elaboración del autor, con base en Policía Nacional Dirección de Carabineros y Seguridad Rural (2012).

\section{Derechos afectados}

La repercusión de la ubicación geográfica y su división política, como lo aclaró en su momento el Gobierno a través del viceministro de Minas, Henry Medina, solo autorizará la explotación a las empresas que cumplan las mejores condiciones técnicas, con el fin de ponerle orden a la minería; para el Gobierno, se trata de una medida en donde todos ganan: el país, el medio ambiente y la minería (Orduz, 2012); lo que en teoría se busca es parar el caos minero que se mueve sin control, eliminando la actividad improvisada y depredadora para darle paso a otra más sustentable, es decir, en otras palabras, se acaba allí la pequeña minería para darle paso a las grandes empresas o multinacionales. Dicha reserva fue declarada por la Agencia Nacional de Minería, mediante la Resolución No. 0045 del 20 de junio del 2012, la cual expresa que 17,5 millones de hectáreas serán las Áreas Estratégicas, en las que se encuentran estas zonas con potenciales mineros (Quintero, 2012).

En efecto, la explotación ilegal de estos minerales desencadena un sinnúmero de situaciones que afectan directa e indirectamente el ecosistema, la población civil, los recursos hídricos y todo lo que encierra el medio ambiente particularmente, porque está arrasando la morada de decenas de especies animales en peligro de extinción, y por ende, se están observando graves consecuencias ambientales para los ríos y humedales del departamento.

De manera que al determinar áreas estratégicas, la ley no contempla un examen juicioso sobre las áreas de explotaciones tradicionales o de minería informal y presenta un vacío respecto a los estudios geológico mineros que debe abordar en orden a acoger o rechazar proyectos estratégicos en tales territorios. Es así como las comunidades tradicionales pese a estar amparadas por las disposiciones legales al concederles la prelación 
para explotar los recursos, no se hallan del todo libres de perjuicio puesto que el respeto de títulos vigentes y suelos concedidos, en esta como en otras zonas del país no es enteramente tomada en cuenta.

\section{Derechos humanos ambientales}

Primeramente es indispensable considerar que la mención que se realiza sobre los DDHH involucrados con el caso objeto de estudio, implica entender que los derechos humanos en el caso colombiano recogidos constitucionalmente, incorporan una estructura de disposiciones que obedecen a estándares internacionales de protección y a los cuales el país se ha vinculado tanto en el ámbito interamericano como de Naciones Unidas.

Los estándares normativos se han plasmado en tratados internaciones de protección de medio ambiente, que han requerido para instrumentalización no sólo de la ratificación de los Estados, también de su propia reglamentación y detalles por parte de los mismo. Colombia por ejemplo ha incorporado desde 1974 el Decreto 2811 Código de recurso Naturales y Ley 99 de 1993 dicho ámbito de protección administrativa.

Al ahondar en el territorio objeto de estudio, cabe enfatizar que los humedales de la Estrella Fluvial del Inírida, uno de los sitios con mayor biodiversidad y más valiosos de la Orinoquia colombiana, que abarca los municipios de Cumaribo (Vichada) y Puerto Inírida (Guainía). Pantanos, de 283.000 hectáreas fundamentales para la regulación de la hidrología y del clima regional, única fuente de agua para las poblaciones ribereñas de la zona transicional OrinocoAmazonas, y que controla las inundaciones al atenuar la acumulación de lluvias, se está viendo afectado directamente por este problema (Silva, 2012).

El daño ambiental en el parque Puinawai cada día es más evidente. Para sacar el coltán y el tungsteno tienen que tumbar árboles. Aunque no hay retroexcavadoras ni grandes máquinas para hacerlo, a punta de pala, sierras y máquinas pequeñas han deforestado más de 26 hectáreas de reserva amazónica, una cifra estimada con los registros aéreos de la zona. Veintiséis hectáreas no suenan mucho pero dado que es un parque de alta biodiversidad y que cada día aumenta sí es preocupante. De forma paralela al problema ambiental, se viene presentando una ola de violencia en respuesta a la extracción de dicho compuesto. En África, especialmente en la República Democrática del Congo, el dinero producto de la extracción del coltán, donde para datos del año 2009 una tonelada podía costar entre 60.000 y 100.000 dólares, esto fue el combustible de un conflicto multilateral que fue llamado la guerra mundial de África, en la que murieron cientos de miles de personas, otras tantas fueron desplazadas y se produjo un desastre ambiental que también involucró a los países vecinos. Las milicias enfrentadas luchaban entre sí por el monopolio del coltán y otros minerales en una espiral interminable de violencia. Por otro lado, las comunidades, particularmente indígenas, pobladoras de la zona viven en la miseria, carecen de agua, luz y cualquier otro servicio público que por las condiciones son de difícil obtención. El ingreso a la zona es casi imposible, ya que habitan en medio de la selva o en las márgenes de los ríos que adicional a las condiciones anteriormente mencionadas se le suma la extrema pobreza. Sólo con observar el abultado abdomen de los niños y la flaqueza de sus extremidades se puede percatar el grado de desnutrición que padecen; asimismo, sus casas son de bahareque y no poseen siquiera inodoro". El mismo estudio del diario El Tiempo da cuenta de cómo los mineros indígenas o colonos que son explotados por las FARC laboran por áreas de unos siete metros, donde abren huecos en la tierra con ayuda de palas y sistemas de inyección de agua a presión. Luego, cuelan la arena negra en unas zarandas para poder extraer las piedras. En un día normal sacan cinco kilos de piedra, y por cada kilo les pagan 9.000 pesos; son 45.000 pesos, que apenas les sirven para comer. Pero en el mercado internacional - en la bolsa de valores de Londres - cada kilo se paga a 162.000 pesos colombianos; es decir, 18 veces más que lo que les pagan a los mineros por extraerlo. Adicional les controlan la comida (Silva, 2012).

Aparte de lo descrito, la mina, está rodeada por improvisados campamentos, las familias de los mineros preparan comida, y en otros más grandes funcionan dos restaurantes, donde cada plato (desayuno, almuerzo o comida) cuesta 12.000 pesos. La gaseosa dos litros vale 15.000 pesos y el arroz crudo, que se les vende a las familias de los mineros, 6.000 pesos la libra, más 1.000 pesos que cobra la guerrilla por dejar entrar cada kilo. El negocio de la alimentación es controlado por comerciantes, que le pagan impuesto a la guerrilla. De otro lado, se presentan los padecimientos y procesos de esclavización que afrontan niños, hombres y mujeres de las comunidades indígenas, campesinos y colonos por parte de estas redes que aprovechan sus necesidades para pagarles cualquier peso por el coltán (Silva, 2012).

\section{De los riesgo de afectación a los derechos fundamentales en general}

Como ya se ha dicho en el aparte anterior, el país ha recogido constitucionalmente una estructura de disposiciones que obedecen a estándares internacionales de protección de DDHH y recogido en la Carta de Derechos de la constitución de Colombia, y a los cuales el país con anterioridad se ha vinculado tanto en el ámbito interamericano 
CIENCIA Y PODER AÉREO | Revista Científica de la Escuela de Postgrados de la Fuerza Aérea Colombiana | Vol. 10 | Enero - Diciembre de 2015

Tabla 1. Derecho afectado y riesgos derivados.

\begin{tabular}{|c|c|}
\hline Derecho afectado & Riesgos derivados \\
\hline \multirow{6}{*}{ Derecho a la vida } & Muerte por desprendimiento de rocas y subsidencias \\
\hline & Muerte por acumulación de gases por falta de ventilación. \\
\hline & Muerte por uso inapropiado de explosivos \\
\hline & Muerte por falta de conocimiento y preparación \\
\hline & Muerte por uso de equipo deficiente \\
\hline & Muerte por inundación de agua \\
\hline \multirow{11}{*}{ Derecho a la salud } & Exposición al Polvo \\
\hline & Exposición a productos químicos \\
\hline & Exposición al ruido y la vibración \\
\hline & Efectos de ventilación deficiente (calor, humedad, falta de oxígeno) \\
\hline & Efectos de esfuerzo excesivo \\
\hline & Espacios inadecuados de trabajo \\
\hline & Equipo inadecuado de trabajo \\
\hline & Mujeres peligro adicional a salud de fetos y niños en lactancia \\
\hline & $\begin{array}{l}\text { Proliferación de enfermedades transmitidas a través del consumo de agua (malaria, es- } \\
\text { quistosomiasis, etc.) }\end{array}$ \\
\hline & Limitado y difícil acceso a los servicios de salud \\
\hline & $\begin{array}{l}\text { Falta de exámenes médicos para la detección por envenenamiento químico y tratami- } \\
\text { ento apropiado }\end{array}$ \\
\hline \multirow{10}{*}{ Derecho al agua } & Continuo deterioro del recurso hídrico \\
\hline & Carecen de suministro de agua potable \\
\hline & No cuentan con servicios adecuados de saneamiento básico. \\
\hline & Contaminación con mercurio, cianuro y químicos \\
\hline & Eliminación directa de relaves y efluentes en los ríos \\
\hline & Daño en aéreas aluviales de ríos \\
\hline & Ríos convertidos en cienos \\
\hline & Daño por erosión y deforestación \\
\hline & Destrucción del paisaje. \\
\hline & Afectación zonas de protección hídrica (nacimientos) \\
\hline \multirow{3}{*}{$\begin{array}{l}\text { Derecho a un } \\
\text { ambiente sano }\end{array}$} & $\begin{array}{l}\text { Daños a la atmosfera por contaminación derivada de la emisión de gases, partículas, } \\
\text { ruido, olores o corrientes de alta temperatura }\end{array}$ \\
\hline & Daños al suelo \\
\hline & Daños a los bosques \\
\hline \multirow{6}{*}{ Derecho al trabajo } & $\begin{array}{l}\text { Afectación de la dignidad humana, en razón a que la labor desempeñada no debe en- } \\
\text { contrarse en situación de explotación, de peligro o impuesta con amenazas }\end{array}$ \\
\hline & No hay condiciones de seguridad industrial y seguridad social \\
\hline & Remuneración baja y de acuerdo a rendimiento en la labor \\
\hline & Trabajo infantil a causa de la pobreza con incidencia sicológica, social y en la educación \\
\hline & Ausencia en creación de cooperativas, empresas y asociaciones. \\
\hline & $\begin{array}{l}\text { Afectado el derecho de prelación en áreas mineras indígenas, comunidades negras o } \\
\text { mixtas }\end{array}$ \\
\hline
\end{tabular}

Fuente: Elaboración del autor, basado en datos de la Defensoría del Pueblo, 2010.

162 | Trasgresión de derechos humanos a raíz del tráfico ilegal de coltán en el Departamento del Guainía 
como de Naciones Unidas, a través de pactos y Convenciones Internacionales de DDHH.

Para el presente caso se revisan particularmente los derechos de vida, salud, agua, medio ambiente y trabajo. Es importante advertir que dicha consagración normativa ha sido complementada con el desarrollo jurisprudencial tanto constitucional como administrativo nacional, los cuales han seguido el enfoque de tribunales internacionales de DDHH como son la Corte interamericana de Derechos Humanos CIDH.

En la investigación realizada con base a los documentos consultados se logró realizar una consolidación de los riesgos derivados cuando se ven afectados derechos fundamentales que se encuentran directamente relacionados con el tema de indagación, como se resume en la Tabla 1.

\section{Efectos en el contexto sociojurídico}

El hecho de que el Estado no haya definido de tiempo atrás y de manera adecuada la propiedad de estos recursos explica muchos de los problemas relacionados con el origen de los títulos mineros en Colombia; lo que permitió que durante décadas se realizara explotación sin el pago de contraprestación alguna y sin las mínimas previsiones ambientales, en especial en la extracción de materiales de construcción, como arcillas, arenas, cantos de río y material pétreo; que solamente hasta la expedición del decreto 2655 de 1988 fueron considerados como minerales y por ende su explotación se dio en términos de informalidad propiciada por una legislación tardía que una vez entró en vigencia, no consideró reconocer derecho alguno a los pequeños explotadores tradicionales de estos recursos, que en su gran mayoría representan familias en línea de pobreza sin mayores posibilidades de formalización e industrialización de su precaria actividad. Con el coltán ocurre lo mismo. Nada ha cambiado este accionar jurídico pues el territorio del Guainía ahora por la explotación del coltán, es vulnerado por la carencia de una política pública definida sobre la minería y sus implicaciones económicas y sociales, deja en manos de extranjeros los escasos desarrollos pero sin mayores contraprestaciones ni para el Estado ni para los territorios en donde se llevan a cabo importantes proyectos mineros (Esquivel, 2001).

En reciente informe de la Procuraduría General de la Nación (2011), se advierte que según la Policía Nacional, la minería criminal financia grupos armados ilegales especialmente en Guaviare, Guainía y Vaupés y fija sus intereses en nuevos yacimientos mineros del coltán como mineral estratégico. Los problemas de criminalidad asociados a la normatividad endeble tienden a aumentar si se tiene en cuenta su alta rentabilidad, el control territo- rial que ejercen en zonas de minerales estratégicos las bandas criminales y los grupos narcoterroristas, los bajos precios que se pagan por regalías con lo cual se estimula el lavado de activos, la carencia de control de la actividad minera por parte del Estado, el confuso y desarticulado marco jurídico que regula la minería, los precios internacionales de algunos minerales y las importantes reservas que de ellos posee el país. La actividad minera es por tanto, de importancia estratégica para los intereses del Estado y sobre ella se ciernen amenazas que afectan la seguridad y la defensa del territorio colombiano sin que existan mecanismos suficientes de orden político, legal, institucional y militar para contener la amenaza.

A pesar de que el Gobierno del presidente Juan Manuel Santos se comprometió desde el inicio de su gobierno con la creación de la Agencia Nacional Minera (ANM), sólo hasta el 3 de noviembre de 2011 mediante decreto 4134 se dio vida a esta Institución, la cual comenzó operaciones el 3 de mayo de 2012 con 19.000 solicitudes de contratos de concesión pendientes de resolver y con un difuso esquema funcional que se soporta aun en delegaciones mineras en cinco departamentos y las antiguas seccionales del Ingeominas, sin la posibilidad de recibir nuevas propuestas de contratos de concesión ya que los términos están suspendidos (Massé, 2012).

Con realidades como las del coltán, aún no se conocen cuáles serán las nuevas reglas en materia de adjudicación de nuevas áreas y los cambios sustanciales en la administración de los recursos mineros por ausencia de reglamentación y por la carencia de una normatividad que contrarreste la explotación a la integridad humana de los pobladores y los trabajadores que se exponen al sometimiento de las redes criminales.

En cuanto a la minería tradicional de subsistencia; el plan de legalización contenido en la Ley 1382 de 2010, fracasó debido a que este instrumento fue aprovechado por quienes sin tener la condición de pequeños mineros ilegales, hicieron uso de este mecanismo para avalar explotaciones recientes, altamente mecanizadas y de grandes impactos ambientales, muchas de ellas en manos de grupos criminales a fin de evadir los requisitos que la ley exige para el ejercicio de la actividad formal. Aun no se sabe exactamente cuáles fueron los resultados de este proceso de legalización de informales pero los problemas presentados por el abuso de este mecanismo llevaron a Ingeominas a suspender las solicitudes de legalización en todo el país desde hace cerca de un año.

La Ley 1450 de 2011, en virtud de la cual se expide el plan de desarrollo del gobierno actual, contemplo algunos 
CIENCIA Y PODER AÉREO | Revista Científica de la Escuela de Postgrados de la Fuerza Aérea Colombiana | Vol. 10 | Enero - Diciembre de 2015

aspectos relacionados con la minería ilegal, en especial el control a la utilización de elementos mecánicos y uso de maquinaria en procesos de legalización de minería de hecho (Artículo 106), definición de áreas de reserva para minerales estratégicos (Artículo 108), control en la comercialización de minerales (Artículo 112), pero no diseñó ninguna estrategia a fin de hacer frente a la criminalidad en la actividad minera siendo este un problema fundamental para la integridad de la población como bien se ha insistido en este análisis.

Cabe anotar que en los últimos 20 años el país ha tenido tres leyes mineras y se espera una cuarta reforma ya que los problemas en la administración del recurso, el ejercicio de autoridad del Estado y el rol que el mismo debe cumplir frente a la minería no están resueltos; como tampoco lo están desde el punto de vista normativo los relacionados con la criminalidad presente en la totalidad de la cadena productiva de la minería. ${ }^{4}$

\section{Impacto y derechos humanos}

Por la importancia estratégica del Guainía para las rutas que los grupos ilegales han impuesto alrededor de la explotación del coltán, el conglomerado humano que en esta actividad participa reúne a niños soldados reclutados por las FARC, a mujeres y ancianos que están a merced de trasnacionales y traficantes. En condiciones abusivas este comercio de la muerte que somete tanto a lugareños indígenas como a campesinos a la extracción del mineral, ha llamado la atención de las organizaciones que velan por los derechos humanos, las cuales han hecho visible esta problemática del Guainía pero hace falta la acción del Estado para que la dignidad de la población sea respetada en tanto se enfrente a las cabezas de las redes y se emita una política minera que cierre el paso a la ilegalidad y al crimen. Como no existen leyes lo suficientemente sólidas para que la acción de las autoridades ejerza vigilancia y contención al delito, el ciclo vicioso se repite y las violaciones a los pobladores se acrecientan (Beltrán, 2010).

Con el consecuente deterioro ambiental, también la práctica de extracción sin los mínimos de seguridad, termina afectando la salud de pobladores quienes se ven expuestos al contacto con la toxicidad inherente al mineral.

Se da el caso que si alguien queda tendido en el camino por el efecto de la extracción no controlada o porque lo guerrilleros eliminan al labriego que intenta huir y no ser sometido a una explotación del mineral de manera

\footnotetext{
${ }^{4}$ El decreto 2655 de 1988 estuvo vigente hasta la expedición de la ley 685 el 15 de agosto del 2001, la cual fue reformada con la Ley 1382 de 2010. En la actualidad cursan en el Congreso proyectos de reforma minera cuyo trámite continúa en la presente legislatura.
}

forzada, la descomposición de los cuerpos que cualquiera puede encontrarse en el camino ofrece un alto riesgo para la salud colectiva. En un territorio donde la proximidad del coltán trae consigo amenazas medioambientales por la inobservancia de los procedimientos, urgen medidas y normas, máxime porque la extracción del coltán provoca graves consecuencias para la salud de los mineros y del medioambiente. A veces el coltán incluye uranio o torio, sustancias de alta toxicidad que son inhaladas por los obreros de modo constante (Corominas, 2008).

La corteza de los árboles es utilizada para separar el coltán del barro: lo que genera una tala indiscriminada de especies que necesitan mucho tiempo para regenerarse. Así mismo, la repentina aparición de un número tan elevado de personas que cazan para alimentarse ha supuesto un profundo retroceso en la biodiversidad de la zona este del país. (Corominas, 2008). Sumado a esto, la deforestación, la debilidad del Estado ante lo ocurrido en zonas de guerra, el sometimiento forzado de niños, mujeres y ancianos a las prácticas ilegales derivadas, ocurre paralelo a esto el tráfico de personas para transportar de manera clandestina el mineral y luego desaparecer. Una evidencia más que la ilegalidad en que tiene lugar la explotación recae en violaciones sistemáticas (IEPRI, 2007).

Ahora bien, sucede con las compañías compradoras lo mismo que lo registrado con la problemática de los diamantes en Sierra Leona: un silencio cómplice y una política de reserva sobre el origen del coltán y los antecedentes criminales que enmarcan la entrega final.

En el entorno globalizado la creación de mecanismos de control son mínimos. Corominas, (2008) sostiene que una visión holística que contribuya a mitigar los problemas causados por las necesidades occidentales y sus consecuentes relaciones comerciales a escala global en torno a la explotación del coltán, puede derivar un frente común contra las violaciones sistemáticas a los derechos humanos. En esa dirección, urge la persecución eficaz de individuos y empresas que violen las leyes en esta materia, esa es otra de las cuestiones que deben ser abordadas con urgencia. Nadie niega que las violaciones a los derechos humanos exacerba todo lo imaginado alrededor de la explotación ilegal de recursos naturales como el coltán pero tal es la inoperancia jurídica y la falta de interés de los Estados de velar por la integridad del personal forzado a esta explotación, que sin duda, amerita llamar la atención por otras vías democráticas que normalmente proceden del quehacer privado (Linares, 2010). Bajo esta realidad, así el departamento se ha convertido en un punto geográfico de explotación y muerte, donde la internacionalización del recurso natural colombiano tiene un alto valor geoestratégico. Según uno 
de los investigadores más serios de la problemática, Michael Klare (2009), en torno al mineral cuatro puntos geográficos del planeta trazan el coltán de mayor potencial industrial que el de Brasil, Egipto y Tailandia, convirtiendo al territorio del Guainía como el segundo en potencial termoeléctrico y de mayor resistencia al calor.

Por las propiedades eléctricas, la industria satelital y armamentística así como el mercado de los ordenadores o móviles demandan con urgencia del mineral ${ }^{5}$ y esto hace que la búsqueda del mismo propicie todo un comercio de afán que hace peligrar la vida de quienes son explotados por los monopolizadores del mercado.

\section{Impacto a la vida}

El $80 \%$ de las reservas mundiales de coltán se encuentra en la República Democrática del Congo (RDC), más concretamente en la región este de Kivu, lo que la convierte en una zona de gran interés para los explotadores. Existen dos bandos que se disputan el control de la extracción: por un lado, las fuerzas de Ruanda y Uganda, unidas a movimientos rebeldes; por otro, el Gobierno de la RDC, apoyado por Angola y Zimbabue. A estos competidores hay que sumarles los intereses de las grandes trasnacionales que contribuyen a perpetuar el conflicto: Barrick Gold Corporation (Canadá), American Mineral Fields y Anglo-American Corporation (Sudáfrica). Todo comercio, ético o no, necesita una red de transporte y las compañías aéreas, entre ellas la belga Sabena, prestan sus servicios a cualquier traficante que desee vender coltán y comprar armas (Altube, 2003). No obstante, cuando el tráfico ilegal atraviesa los territorios ricos en recursos naturales, tal como Laufer (2010) afirma, será un agravante más para el Estado colombiano en materia de derechos humanos:

Colombia es un punto ineludible para los sabuesos de la riqueza genuina de la tierra puesto que el privilegio de sus suelos resulta ser bastante atractivo para los zares del comercio de la mineralogía mundial. No tardarán en percatarse que el coltán de las zonas selváticas de este país suramericano tendrá el potencial de abastecimiento que ellos necesitan y mejor aún, ante la falta de leyes y una plataforma jurídica que impida la extracción transnacional y en condiciones infrahumanas y sin garantías de ningún tipo para quienes son forzados a cambio de unas irrisorias monedas en el mejor de los casos a extraer del corazón de los suelos el preciado mineral, el negocio entonces se les facilitará aquí mejor que en cualquier otro lugar del mundo. Pero si su gobierno no toma cartas en el

${ }^{5}$ Es revelador el caso de Sony que tuvo que retrasar el lanzamiento de su videoconsola Playstation2 por una escasez en el suministro de este material. (Pozas) asunto, con sus trabajadores mineros sucederá lo mismo que con los de los diamantes en Sierra Leona y el mismo coltán en Nigeria, que ríos de sangre acompañaron cada piedra ante la complicidad y el silencio de las compañías que en nada las afecta las pérdidas y las degradaciones humanas. (s.p.).

En África por ejemplo, los esclavos que trabajan en las minas de coltán superan los 20.000 y su procedencia es tan diversa como las causas que les empujan a esta situación. Campesinos que han cambiado de oficio porque sus tierras no pueden sustentar a sus familias; refugiados y prisioneros a los que les prometen una reducción de la condena; niños obligados a trabajar porque pueden acceder a minas más estrechas. Estos obreros se dedican a la extracción del coltán durante el día y por la noche malviven en la selva sin ningún tipo de infraestructura (Machado, 2007).

En palabras del propio Klare: "una estrategia basada en la cooperación a escala mundial sería más efectiva que el conflicto". (párr. 9) Propone la creación de instituciones sólidas que regulen el flujo de recursos y actúen como moderadores en caso de escasez. Klare defiende que, a largo plazo, los intereses deben ir encaminados a suministrar los recursos de manera equitativa lo que sin duda iría en contra de las intenciones de algunos Estados y empresas que serían reacias a ceder su control a las agencias internacionales (Corominas, 2008).

Complementario a la preocupación legislativa, un estudio de Lunar y Martínez (2007) revela que "estudios mineralógicos y geoquímicos detallados sobre muestras de coltán de distintas áreas permitirían servir de herramienta para identificar los afloramientos geológicos de procedencia y ayudar así a controlar su tráfico ilegal" (párr., 8). De esta manera se podría afrontar el problema del coltán según se ha hecho con los diamantes: creando mecanismos de control que avalen que las extracciones de coltán se realizan con las garantías necesarias. Dentro de esas garantías, la vida humana debe blindarse en esos marcos legislativos en tanto el consumo sea un consumo responsable, que sustraiga de la explotación del mercado todo tipo de vejámenes y atentados contra la integridad humana. De modo concreto, el Gobierno colombiano debe operar en ese rumbo para asegurar que las libertades humanas de los pobladores que habitan el Guainía no se violenten por una actividad que como no posee el amparo del Estado expresado este en una reglamentación cabal que proteja la dignidad humana, está abocada a un círculo de muerte.

En la Figura 6 se condensa lo que Klare interpreta de los vacíos de una regulación para el mercado del coltán. 
Los equipos técnicos que plantean la regulación en las zonas de explotación, desconocen a los grupos humanos asentados en las zonas.

No existe una estrategia de comunicación ambiental diseñada y aplicada como herramienta de apoyo que sensibilice a las autoridades de las regiones ricas en coltán.

El sistema de información geográfica de las zonas es débil y no tiene contacto con los verdaderos afectados.

Los planes urbanos y rurales no se elaboran participativamente. No poseen carácter socializador ni concertado a nivel de Gobierno local.

En los países donde por causa de la extracción del coltán no se cuentan con normas, estrategias y acuerdos que impidan la instrumentación de las personas y su explotación, la justicia internacional debe promover los correctivos.

Figura 6. Vacío de la regulación.

Fuente: elaboración del autor, basado en Altube (2003).

Actores participantes del fenómeno

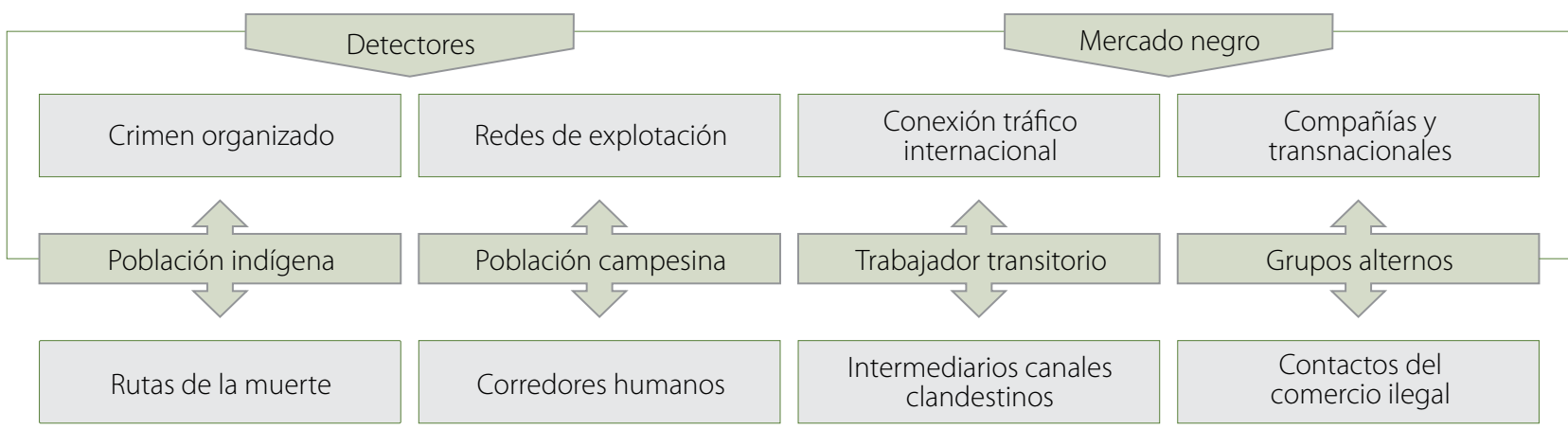

Figura 7. Actores participantes del fenómeno.

Fuente: Elaborado por el autor con base en Klare (2009).

Por su parte, al evaluar lo que ocurre alrededor de la explotación del coltán y dados los hallazgos aquí relacionados, la consulta conceptual, deja en claro que los trabajadores ilegales de quienes manejan y administran el mercado negro del mineral, aprovechan que los países ricos en el recurso pero faltos de una política de vigilancia, control y gestión por el respeto a los derechos humanos, continúan en desinterés sin que se rastreen todas las rutas del crimen en torno a la extracción y comercialización que por lo general utiliza corredores humanos para irrumpir en la venta internacional.

En la Figura 7, se describe el planeamiento criminal del mercado ilegal del coltán y cómo se surte de la explotación humana de los grupos en cuestión. Mientras que en los siguientes recuadros, para el efecto evaluativo de lo que significa el mercado clandestino del coltán y el impacto criminal que su explotación encierra en territorio del Guainía, se ofrece una semblanza de la realidad que tiene lugar en África y que debe servir como un llamado a la regulación y vigilancia urgente en Colombia frente a esta realidad.

\section{Conclusiones}

A la pregunta de investigación de si la explotación ilegal del coltán afecta la DDHH derechos humanos de las comunidades del territorio de Guainía, los aspectos puntuales que se pueden concluir tras el examen efectuado en este contenido, atiende a despejar las dudas respecto a si se respeta la riqueza territorial en medio del ambiente delictivo que conlleva esta práctica.

Una primera conclusión es que la no regulación consolidada acerca de la explotación del mineral del coltán posibilita que su práctica derive en ilegal, con las consecuentes dinámicas de despliegue modal de conductas en territorio de conflicto armado.

La afectación de bienes jurídicos penales vinculados con la vida, la salud, el trabajo y el medio ambiente, no es exclusiva del área de trajo de la justicia penal, sino que involucra antes que todo una amenaza y eventual vulneración de DDHH hoy consagrados nacionalmente pero recepcionados de estándares internacionales sobre la materia.

Los DDHH y sus impactos, con ocasión de la explotación ilegal del mineral del coltán en zona de conflicto armado, llevan necesariamente a la evaluación de políticas públicas relacionadas con la orientación y direccionamiento que tiene el Estado con ocasión de estas acciones de intervención no legal sobre recursos naturales no renovables. 
De esta manera, el estudio aquí realizado trasciende el análisis de la normativa de DDHH involucrada y se vincula igualmente con la implementación de las políticas públicas estatales relacionadas con dichos derechos.

En este sentido, dichas políticas se vinculan asuntos étnicos de pobladores de la zona, políticas de seguridad ciudadana, política criminal asociadas a conductas punibles presentes, política ambiental, política sanitaria y política laboral del trabajo minero.

En este sentido, la desarticulación del gobierno en materia de una política pública que favorezca los derechos de los grupos nativos como primeros beneficiarios legítimos de las riquezas naturales de su suelo, empeora la situación de derechos humanos en esta zona del país por cuanto en aras de la utilidad pública e interés nacional se desconocen los mínimos de calidad de vida de estas colectividades. Por ende, la identificación y atención de la población de mineros tradicionales y de subsistencia en el departamento de Guainía, debe comprometer a las entidades responsables de esta materia, no sólo en los procesos de legalización minera, también en la disposición de áreas de reserva especial que involucren población indígena y afro descendiente que regularmente habitan la zona objeto de estudio.

Así, en la complejidad de defender el desarrollo sostenible del Guainía, los balances de la criminalidad que tiene lugar alrededor de la explotación ilegal del Coltán, no exime a las autoridades de responsabilidad ante la falta de control de las prácticas que lesionan severamente los derechos laborales de los indígenas puesto que el tráfico soterrado del mineral, se encuentra fuera de todo concepto de responsabilidad técnica, ambiental y social, hecho que propicia aprovechamiento irracional de la mano de obra de los miembros de las comunidades, desconocimiento de sus principios de territorialidad y autonomía e interferencia en el logro de su Plan de Vida.

La respuesta hallada al presente interrogante tiene un denominador común y es que no se ha logrado el punto de inflexión entre el Estado y las comunidades por la falta de control del Gobierno frente al delito creciente que en Guainía tiene lugar alrededor de la explotación ilegal del coltán.

Por su parte, el mejoramiento en los procesos y las prácticas amigables al medio ambiente son indispensables a fin de preservar los yacimientos y los recursos naturales en general pero en materia de derechos humanos queda por trabajar un soporte sustancial de amparo y protección a las víctimas de las redes criminales que operan en razón de la explotación del coltán dado que esos corredores de explota- ción humana, sometimiento de niños, mujeres y hasta ancianos, engruesan los réditos del crimen internacional.

De igual modo, es necesario el concurso de las instituciones dedicadas a perseguir y controlar el lavado de activos y la actividad financiera, con el propósito de desvertebrar las redes creadas por estas organizaciones y de esta forma disminuir su accionar y su capacidad de lesionar las libertades y los derechos humanos de los grupos y asentamientos indígenas y campesinos.

En cuanto a los datos suministrados por la Policía Nacional, donde se registraron operaciones que dan cuenta de minas intervenidas, capturas, y kilogramos de coltán incautados, se demuestra que en la zona se explota este mineral de forma ilegal, y posiblemente las reservas de este, en el área son considerables, el esfuerzo realizado para atacar ese flagelo se evidencia con los picos mostrados, pero desafortunadamente las cantidades que no se logran decomisar pueden ser de la misma cantidad o mayores a las detectadas. Asimismo, las variables del problema son muchas, no se cuenta con los conocimientos sobre el mineral y adicionalmente no hay equipos que ayuden a la detección del mineral.

Cuando la explotación humana en Guainía se asocia a un recurso natural que empodera la alta tecnología de hoy, donde redunda en beneficio de una industria, un análisis como este apunta a trasladar a la reflexión de las mesas decisorias, una política que impida el comercio criminal, la destrucción del hábitat, el genocidio y la esclavitud a que se someten los pobladores en razón de las redes que en esta parte del país operan.

\section{Referencias}

Alianza para explotación ilegal del coltán. (7 de octubre, 2012). El Nuevo Siglo. [En línea] Disponible en http://www. elnuevosiglo.com.co/articulos/10-2012-alianza-paraexplotaci\%C3\%B3n-ilegal-del-colt\%C3\%A1n.html

Altube, R. (2003). La fiebre del coltán: el imperialismo continúa. Revista Pueblos. [En línea] Disponible en http://www.nodo50. org/observatorio/coltan.htm

Bothe, M., Bruch, C., Diamond, J., Jensen, D. (2010). El derecho internacional y la protección del medio ambiente durante los conflictos armados: lagunas y oportunidades. International Review of the Red Cross No 879. [En línea] Disponible en https://www. icrc.org/spa/assets/files/review/2010/icrc-003-0879-bothe.pdf

Colombia. Congreso de la República. (2010). Ley 1382. (09 de febrero, 2010). Por la cual se modifica la Ley 685 de 2001 Código de Minas. Diario Oficial. Bogotá, D.C. No. 47618. 
CIENCIA Y PODER AÉREO | Revista Científica de la Escuela de Postgrados de la Fuerza Aérea Colombiana | Vol. 10 | Enero - Diciembre de 2015

Colombia. Congreso de la República. (16 junio, 2011). Ley 1450. Por la cual se expide el Plan Nacional de Desarrollo 2010-2014. Diario Oficial. Bogotá, D.C. No. 48102.

Conflictos por control de Coltán en Colombia temen las autoridades. (12 de diciembre, 2009). El Tiempo. [En línea] Disponible en Recuperado de http://www.eltiempo.com/archivo/documento/CMS-6795427

Corominas, C. (2008). La maldición de África. El Ecologista No 56. [En línea] Disponible en http://www.ecologistasenaccion.org/article17868.html

Corte Interamericana de Derechos Humanos. (2001). Caso de la Comunidad Mayagna (Sumo) Awas Tingni Vs. Nicaragua. [En línea] Disponible en http://www.corteidh.or.cr/docs/casos/articulos/Seriec_79_esp.pdf

Defensoría del Pueblo Colombia. (2010). Minería de hecho en Colombia. Defensoría Delegada para los Derechos Colectivos y del Ambiente. Bogotá D.C.: Imprenta Nacional de Colombia. ISBN 958-958-8571-29-4

Diaz-Struck, E. \& Poliszuk, J. (2012). The illicit trade of coltan. Venezuela emerges as new source of "conflict"minerals Retrieved from http://www.icij.org/projects/coltan/venezuela-emergesnew-source-conflict-minerals

Esquivel, R. (2001). Colombia Indefensa. Bogotá: Espasa Hoy, Editorial Planeta.

Galeano, J. (2011). La Gobernanza Minera: El Caso del Coltán en Colombia. [En línea] Disponible en https://www.academia. edu/8113026/LA_GOBERNANZA_MINERIA_EL_CASO_DEL_ COLTAN_EN_COLOMBIA

García, C. (12 de noviembre, 2012). Viaje al corazón de la minería ilegal en Guainía. La Silla Vacía. [En línea] Disponible en http:// lasillavacia.com/historia/viaje-al-corazon-de-la-mineria-ilegalen-guainia-37128

Gómez, I. (25 de febrero, 2005). Amenaza en el Puinawai. El Espectador. [En línea] Disponible en http://www.elespectador.com/ noticias/investigacion/amenaza-el-puinawai-articulo-328717.

La guerra por el coltán. (21 de noviembre, 2009). Revista Semana. [En línea] Disponible en http://www.semana.com/nacion/articulo/la-guerra-coltan/110119-3

La selva herida por la minería. (29 de marzo, 2013). Revista Semana. [En línea] Disponible en http://www.semana.com/nacion/articulo/la-selva-herida-mineria/338157-3

Londoño, J. (26 de noviembre, 2009). Congelaran áreas donde existen reservas de "oro azul". [En línea] Disponible en http:// www.portafolio.co/archivo/documento/CMS-6683267

Lunar, R., Martínez-Frías, J. (26 de septiembre, 2007). El coltán, un mineral estratégico. El País: Diario de España. [En línea] Disponible en http://elpais.com/diario/2007/09/26/futuro/1190757604_850215.html

Machado, A. (14 de junio, 2007). Cuando un diamante es más peli- groso que un león. Los bosquimanos gana y gwi del Kalahari. Ecología Política. № 33.

Marín, C. (2013). Tantalio y Niobio: Metales Refractarios. Desmitificando el "Coltán". [En línea] Disponible en http://www.metalactual. com/revista/16/materiales_coltan.pdf

Massé, F. (2012). Actores Armados llegales y Sector Extractivo en Colombia. V Informe 2012. CIT pax Colombia. Observatorio Internacional DDR - Ley de Justicia y Paz.

Michael, K. (2009). Rising Powers, Shrinking Planet: The New Geopolitics of Energy. New York. Metropolitan Books Pp. 127, 132, 133, $137,211,217$.

Nullvalue. (25 de marzo, 2012). Destruirán la maquinaria de la minería ilegal. El Tiempo. [En línea] Disponible en http://www. eltiempo.com/archivo/documento/MAM-5308133

Orduz, N. (05 de agosto, 2012). La reserva minera de la Amazonia que el Ministro de Ambiente aprobó sin estudiar. La Silla Vacía. [En línea] Disponible en http://lasillavacia.com/historia/la-reserva-minera-en-la-amazonia-que-el-ministro-de-ambienteaprobo-sin-estudiar-35135

Parques Nacionales Naturales de Colombia. (2012). Ubicación Geográfica de la Reserva Nacional Natural Puinawai. [En línea] Disponible en https://www.parquesnacionales.gov.co/PNN/ portel/libreria/php/decide.php?patron=01.012206

Policía Nacional (2012). Datos Estadísticos. Dirección de Carabineros y Seguridad Rural

Pozas, P. (s.f.)."Coltán: El mineral de la muerte“. Proyecto Gran Simio (GAP/PGS-España) [En línea] Disponible en http://simiomobile. com/downloads/coltan_mineral_muerte.pdf

Procuraduría General de la Nación. (2011). Minería llegal en Colombia. Informe Preventivo.

Quintero, J. (25 de noviembre, 2012). Coltán: viaje al jugoso negocio que controla la guerrilla en Guainía. El Tiempo. [En línea] Disponible en http://www.eltiempo.com/archivo/documento/ CMS-12399487

Sarralde, M. (6 de octubre, 2012). Patrullera fluvial combatirá minería ilegal en ríos del Guainía. El Tiempo. [En línea] Disponible en http://www.eltiempo.com/archivo/documento/ CMS-12285505

Silva, J. (14 de julio, 2012). En riesgo, uno de los lugares con más biodiversidad por minería ilegal. Los humedales de la Estrella Fluvial de Inírida siguen sin ser declarados zona protegida. El Tiempo. [En línea] Disponbile en http://www.eltiempo.com/ archivo/documento/CMS-12030010

Tantalum - Niobium International Study Center (2012). [En línea] Disponible en http://tanb.org/

The International Consortium of Investigative Journalists (2012). Map: where illegal coltan mining thrives. [En línea] Disponible en http://www.icij.org/projects/coltan/map-where-illegalcoltan-mining-thrives 